\title{
Retropubic Prostatectomy- Innovations to Reduce Complications Leading to Smooth Recovery
}

\author{
M. Subrahmanyam, G. Vamshikrishna, G. Harikrishna \\ Department of General Surgery, Kamineni Institute of Medical Sciences, Narketpally, T. S., India
}

Email address:

subrahmanyam_mutya@yahoo.com (M. Subrahmanyam)

\section{To cite this article:}

M. Subrahmanyam, G. Vamshikrishna, G. Harikrishna. Retropubic Prostatectomy- Innovations to Reduce Complications Leading to Smooth Recovery. Journal of Surgery. Vol. 5, No. 2, 2017, pp. 15-17. doi: 10.11648/j.js.20170502.11

Received: January 25, 2017; Accepted: March 9, 2017; Published: March 20, 2017

\begin{abstract}
Introduction: Open prostatectomy/adenoma enucleation remains a valuable surgical option in treating large obstructing prostates in patients with large gland volume. We report our series of retropubic prostatectomies with innovative methods to reduce the complications and lead to smooth recovery. Patients and Methods: A total of 75 patients with B PH were treated by retropubic prostatectomy from 2005 to 2015. Patient's demographical, clinical, pre- and postoperative data and final histology were recorded. 3 way Foley's catheter before surgery was kept in the bladder and haemostasis was obtained by applying traction over the prostatic fossa. Results: The mean weight of prostatic adenoma was $82 \mathrm{gm}$., the smallest being $70 \mathrm{gm}$. and the largest $192 \mathrm{gm}$. Only 2 patients required intra operative blood transfusion. The catheter was removed on the 5 th post-operative day. $94 \%$ of the patients voided with a good stream with little discomfort after one week. only one patient had incontinence of urine which improved subsequently over a period of 6 to 8 weeks. There was no mortality and no reexploration for clot retention was required in any patient, Conclusion: Millin's prostatectomy popularized over half a century ago continues to be a valuable option for the surgical treatment of high-volume prostate glands with excellent outcomes for patients with innovative methods.
\end{abstract}

Keywords: Prostatectomy, Clot Retention, Millin's Prostatectomy

\section{Introduction}

The surgical treatment of BPH has undergone important changes during the recent years. The Minimally invasive therapies including laparoscopy and robotic assisted laparoscopy has been used for treatment of BPH [1]. HoLEP has emerged as a versatile and very effective modality [2]. Open prostatectomy, once being among the main treatment modalities for $\mathrm{BPH}$, has been relegated to a very small position in developed countries rising the question whether open prostatectomy for $\mathrm{BPH}$ has become obsolete. In developing countries, however, the entry and widespread application of the new modalities have been slow and hampered by lack of resources, inexperienced staff and unavailability of specialists. Thus, open prostatectomy continues to be among the main treatment options in these countries [3]. Open prostatectomy started a century ago with the first description of a planned open enucleation of the prostate by Bellfield [4] and later by Frayer in 1900 [5]. The retropubic approach was first described and popularised by
Millin in 1945 [6, 7]. Today, the majority of patients who require an operation for BPH undergo TURP. However approximately $5 \%$ to $10 \%$ of them undergo some type of open prostatectomy [8]. Hemorrhage, is the main complication of retropubic prostatectomy, followed by lekages, incotinence and wound infections etc. We tried a few innovations like introducing a $3 \mathrm{w}$-ay Foley's catheter before starting surgery and using the inflated balloon to secure haemostatsis by applying traction over it. We report here with our experience with retropubic prostatectomy.

\section{Material and Methods}

75 cases of retropubic prostatectomy for BPH carried out at General Hospiatalspital, Sangli and Kamineni Institute of Medical sciences, Hospital from Jan. 2000 to Dec. 2015 formed material for the study.

Total $12 \%$ of our patients of benign prostatic hyperplasia requiring intervention during the study period $(n=625)$ underwent retropubic prostatectomy. The decision to subject 
the patient to open surgery was based mainly on prostatic size, detected on abdominal ultrasonography, digital rectal examination and cystoscopy. The patients with associated bladder pathology warranting open surgery and with larger glands were subjected to open prostatectomy.

The gland size was finally determined on cystoscopy, performed just prior to surgery. The patients with gland size more than 60 to 70 gms and for whom the urologist felt that the resection time may extend beyond 60 minutes were subjected to open retropubic prostatectomy.

The procedure performed was standard transcapsular retropubic prostatectomy, under spinal anaestahesia, 3- way 20F Foley's catheter was kept in the bladder before starting surgery. Extra peritoneal exposure of the prostate was carried out by Pfannensteil incision. By making an incision over the prostatic capsule prostate was enucleated. The presence of urethral catheter has facilitated to get a good plane and a clean separation. The prostatic fossa was packed with roller gauze and pressure was applied for 5 minutes, Traction was applied to the catheter and maintained by fixation to the thigh as described earlier for transvesical prostatectomy [9]. The bladder was irrigated with normal saline till the return was clear.

The wedge resection of bladder neck was carried out if bladder neck was found to have a relatively small opening along with advancement of bladder mucosa into the prostatic fossa. The watertight closure of transverse capsulotomy was accomplished with no. 1 chromic catgut. No suprapubic catheter was kept in any case. Postoperative irrigation was given till next morning. The traction was maintained for $6 \mathrm{hr}$ at the end of which time it was discontinued. The catheter was removed on $5^{\text {th }}$ postoperative day in an ambulatory patient with clear urine.

\section{Results}

The mean age of the patients who underwent open retropubic prostatectomy was 65 years, the youngest being $56 y e a r s$ old and the oldest 82 years old. The mean weight of prostatic adenoma was $82 \mathrm{gm}$., the smallest being $70 \mathrm{gm}$. and the largest 192gm.

2 patients had associated small bladder calculi which could be removed through the same capsulotomy incision. Wedge resection of bladder neck was done in one patient who had bladder neck as it was found to have narrow opening. The histopathology showed benign prostatic hyperplasia in 71 patients and prostatic intraepithelial neoplasia in 4 patients. The prostate specific antigen was in normal range in all these patients. Table 1 shows the patient data.

Only 2patients required intra operative blood transfusion. 72 patients $(96 \%)$ voided urine with a good stream with little discomfort after removal of catheter. Only one patient had incontinence of urine which improved subsequently over a period of 6 to 8 weeks. One patient had a suprapubic fistula which healed after 2 weeks of conservative management. The mean duration of surgery was 30 minutes (range 20-38 minuates). The mean hospital stay was 6. 5days (range 5- 10days). There was no hemorrhage intra-operatively or in the immediate post-operative period. No patient needed reexploration for clot retention. There was no mortality. Urine culture before surgery showed E. Coli in two patients, but became sterile after treatment with antibiotics,

We encountered superficial wound infection in 1 patient who had post-operative leak, which was controlled with wound dressings.

Table 1. Data from patients.

\begin{tabular}{ll}
\hline Total No. of patients & $\mathbf{7 5}$ \\
\hline Age $(\mathrm{yr})$ & \\
Mean & 65 \\
Range & $(56-82)$ \\
Weight of prostate & \\
Mean & $82 \mathrm{gm}$. \\
Range & $(70-192 \mathrm{gm})$. \\
operation time & \\
Mean & 30 mins. \\
Range & $(20-38$ mins. $)$ \\
\hline
\end{tabular}

\section{Discussion}

Surgical interventions for benign prostatic hypertrophy have significantly reduced with the advent of meadical therapies for enlarged prostate. Number of prostatectomies decreased over $30 \%$ in U.S. as per a survey based on number of males enrolled in the Medicare programme [10].

However, TURP remains the gold standard of treatment of BPH and has stood the test of time. The risks associated with TURP like haemorrhage and TUR syndrome increases with increase in resection time, size of gland and age. Mebust et al [11] in his study reported increased incidence of TUR syndrome and haemorrhage if the gland is more than $45 \mathrm{gms}$ and resection time is more than 90 mins. Hence, open surgery does play an important role especially in large size glands. There are few conditions in which TURP cannot be performed due to technical reasons like ankylosis of hips preventing dorsal lithotomy position. Associated bladder pathologies like calculi, diverticulum also warrant open surgery [8].

One of the essential problems of prostatic surgery, no matter which type has always been the question of operative haemostasis. Recognising the marked vascularity of the prostate and the excessive bleeding that might occur during surgery, many authors have modified the original technique described by Millin's [6]. Dettmar [12] described continuous sutures of the edges of bladder neck to achieve complete separation of the bladder cavity from prostatic bed thereby preventing blood entering the bladder leading to clot retention. The value of ligation of dorsal vein complex and lateral pedicles have made it possible to perform the enucleation of adenoma in an almost bloodless field avoiding the need for blood transfusion, as described by Walsh et al [8].

The retropubic approach also allows excellent anatomic exposure and visualisation of interior of the prostatic cavity for residual adenoma and bleeding points. We have not 
encountered haemorrhage of severe nature in any case and only 2 of 75 patients required intra operative blood transfusion. A slight red colour of urine was common on the first and second day after the operation. We feel the pressure applied by the inflated ballon over the prostatic fossa helped in securing complete haemostasis. With the retropubic approach accurate and sharp division of the urethra is possible decreasing the risk of incontinence. Presence of catheter has helped in a getting good plane. Only patient had this complication and the patients improved over 6 to 8 weeks on conservative management. The mean duration of hospital stay was 6.5days (range 5-10 days).

Long et al [13] in a 36 year study of 361 retropubic prostatectomies reported 3 deaths and $28 \%$ post-operative complicatiopns. zaggoshi [14] in a study of 3000 retropubic prosatatectomies reported excellent early results. Zambolin et al [16] reported their experience with 385 retropubic prostatectomies in Italy. There was no mortality intraoperatively or in the immediate postoperative period. Servadio [17] reported on 408 retropubic prostatectomies and 262 TURPs. Total hospitalization, operating time and complications were better in the long run in the retropubic prostatectomy group compared with the TURP group. He concluded that open prostatectomy still has a respectable place in urology and therefore, should be considered and also taught to residents for use in dealing with large glands. In our experience with 75 retropubic prostatectomies we observed, it is safe, less time-consuming and associated with minimal morbidity. Hence we feel that it is a good alternative for TURP in large size glands of benign prostatic hyperplasia.

\section{Conclusion}

Retropubic transcapsular prostatectomy, securing homeostasis with inflated ballon of Foley's catheter is a safe, practical and affordable alternative to various minimally invasive therapies for benign prostatic enlargement.

\section{References}

[1] Mariano MB, Tefilli MV, Graziottin TM, Morales CM, Goldraich IH. Laparoscopic prostatectomy for benign prostatic hyperplasia - a six-year experience. Eur Urol 2006; 49: $127-31$

[2] Kuntz RM. Current role of lasers in the treatment of benign prostatic hyperplasia (BPH). Eur Urol 2006; 49: 961-9.
[3] Adam C, Hofstetter A, Deubner J, Zaak D, Weitkunat R, Seitz $\mathrm{M}$ et al. Retropubic transvesical prostatectomy for significant prostatic enlargement must remain a standard part of urology training. Scand J Urol Nephrol 2004; 38: 472-6.

[4] Bellfield WT. Operations on the enlarged prostate with a tabulated summary of cases. Am J Med Sci 1890: 100: 439.

[5] FreyerP. A new method of performing prostatectomy. Lancet 1900: 1: 774 .

[6] Millin T. Retropubic prostatectomy. A new extravesical technique. Report on 20 cases. Lancet 1945: 2: 693.

[7] Millin T. Retropubic Prostatectomy. J Urol 1948: 59: 267-274.

[8] Walsh PC. Osterling JE. Improved hemostasis during simple retropubic prostatectomy. J Urol 1990: 143: 1203-04.

[9] Subrahmanyam. M. A simple technique to achieve homeostasis and prevent clot retention in suprapubic prostatectomy. Tropical doctor 1998, 28: 250.

[10] Holtgrewe HL. Economic issues and the management of benign prostatic hyperplasia. Urology 1995. 143: 2013-14.

[11] Mebust WK, Holtgrewe HL, Cockett ATK, Peters PC and writing committee. Transurethral prostatectomy: immediate and postoperative complications. A co-operative study of thirteen participating institutions evaluating 3,885 patients. $\mathrm{J}$ Urol 1989: 141: 243-247.

[12] Dettmar H. Modification of technique for retropubic prostatectomy: Report of 100 cases. J Urol 1959; 81: 558-561.

[13] Long RM, Thomas AZ, Browne C, Aisinnawi M, Ul-islam J, McDermott TE etal. A 30-year experience of Millin's retropubic prostatectomy: Has this classic operation derived by a President of the College in Ireland stood the test of time? Ir J Med Sci. 2015, 184: 341-4.

[14] Zargooshi J. Open prostatectomy for benign prostate hyperplasia: short-term outcome in 3000 consecutive patients. Prostate Cancer and Prostatic Diseases 2007, 10;374-77.

[15] Trivedi VD, 3 Anandkar MG, SAlve -Satwekar A clinical revie $\mathrm{w}$ of fifty consecutive cases of retropubic prostatectomy for benign prostatic hyperplasia. Indian journal of urology 2000, 16: 122-25.

[16] Zambolin T, Scamzi M, Tralceh, De Luca V, Magri V, Panizz $\mathrm{E}$ et al. Retropubic adenectomy (Millin's technique). Our experience. Arch. Ital. urol. Androl. 1995, 67: 105-7.

[17] Servadio C. Is open prostatectomy really obselete? Urology 1992, 40: 419-21. 